\title{
Objective Definition of the Indian Summer Monsoon Onset*
}

\author{
BIN WANG AND QINGHUA DING \\ Department of Meteorology, and International Pacific Research Center, University of Hawaii at Manoa, Honolulu, Hawaii \\ P. V. JOSEPH \\ Department of Atmospheric Science, Cochin University of Science and Technology, Cochin, India
}

(Manuscript received 11 June 2008, in final form 4 December 2008)

\begin{abstract}
The onset of the Indian summer monsoon (ISM) over the southern tip of the Indian peninsula [also known as monsoon onset over Kerala (MOK)] has been considered the beginning of India's rainy season. The Indian Meteorological Department (IMD) makes an official prediction of ISM onset every year using a subjective method. Based on an analysis of the past 60-yr (1948-2007) record, the authors show that the onset date can be objectively determined by the beginning of the sustained $850-\mathrm{hPa}$ zonal wind averaged over the southern Arabian Sea (SAS) from $5^{\circ}$ to $15^{\circ} \mathrm{N}$, and from $40^{\circ}$ to $80^{\circ} \mathrm{E}$. The rapid establishment of a steady SAS westerly is in excellent agreement with the abrupt commencement of the rainy season over the southern tip of the Indian peninsula. In $90 \%$ of the years analyzed, this simple and objective index has excellent agreement with the onset dates that are subjectively defined by the IMD. There are only $3 \mathrm{yr}$ of the past $60 \mathrm{yr}$ during which the two onset dates differ by more than 10 days, and none of them perfectly reflects the MOK.

A prominent onset precursor on the biweekly time scale is the westward extension of the convection center from the equatorial eastern Indian Ocean toward the southeast Arabian Sea. On the intraseasonal time scale, the onset tends to be led by northeastward propagation of an intraseasonal convective anomaly from the western equatorial Indian Ocean. The objective determination of the onset based on the SAS low-level westerly is a characteristic representation of the complex process of the ISM onset. Given its objectiveness and its representation of the large-scale circulation, the proposed new onset definition provides a useful metric for verifying numerical model performance in simulating and predicting the ISM onset and for studying predictability of interannual variations of the onset.
\end{abstract}

\section{Introduction}

Monsoon onset over Kerala, India (MOK), has been considered as the beginning of the Indian principal rainy season: the southwest monsoon season or simply the (summer) monsoon season. Over $70 \%$ of the annual rainfall in India occurs during the summer monsoon season from June to September (Parthasarathy et al. 1994). The date of MOK, which marks the beginning of the monsoon rains over the southern Indian peninsula, is an important

\footnotetext{
* School of Ocean and Earth Science and Technology Publication Number 7589 and International Pacific Research Center Publication Number 561.

Corresponding author address: Bin Wang, Department of Meteorology, and International Pacific Research Center, University of Hawaii at Manoa, 2525 Correa Rd., Honolulu, HI 96822. E-mail: wangbin@hawaii.edu
}

event in the socioeconomic life of the people of India, particularly in agricultural planning that affects food production and the living of over one billion people.

The MOK is associated with a large area of organized rainfall caused by deep convection extending eastward a few thousand kilometers from the low-latitude regions of the Arabian Sea in the north Indian Ocean (Joseph et al. 1994). The moisture required for this large area of rainfall is mainly produced in the south Indian Ocean and carried to the convective heat source associated with MOK by a strong cross-equatorial low-level jet stream (LLJ) (Findlater 1969; Joseph and Sijikumar 2004). The cyclonic shear vorticity region of the LLJ produces deep convection and monsoon rainfall by Ekman pumping of air, rich in moisture, from the atmospheric boundary layer. Thus, the MOK that marks the beginning of the LLJ is important to a large part of the globe, namely, the tropical Indian Ocean, South Asia, and the western North Pacific Ocean. 
Understanding characteristics of the MOK and predicting the onset date has been a topic of debate and research for more than 60 years. Diagrams depicting isopleths of the normal dates of monsoon rain onset over India were prepared by the India Meteorological Department (IMD) back in 1943 (IMD 1943; IMD weather information is available online at http://www.imd.gov. in). These were based on 5-day rainfall at a large number of stations. Even though more than 60 years have passed, these maps of normal onset dates are still in use by operational forecasters. Since the 1940s the attempt to understand and predict the onset dates of the Indian summer monsoon (ISM) has been continued with increasing available data and computing resources. During the 1950s Ramdas et al. (1954) attempted to predict onset dates over the west coast of India. In the 1960s IMD introduced several forecasting manuals to describe various facets of the monsoon including its onset (Ananthakrishnan et al. 1967). Research continued through the 1970s (e.g., Reddy 1977; Subbaramayya and Bhanukumar 1978), the 1980s (e.g., Saha and Saha 1980; Kung and Shariff 1982; Deshpande et al. 1986; Joseph and Pillai 1988), the 1990s (e.g., Rajeevan and Dube 1995), and into the current decade (e.g., Ghanekar et al. 2003). In spite of all this research and the additional information available, no one could make fundamental changes to the onset dates published in 1943 by IMD.

The date of the MOK is declared by IMD every year based on subjective estimates prepared by operational forecasters. Regarding this, the following is quoted from Ananthakrishnan and Soman (1988):

\begin{abstract}
"Although the onset of monsoon is associated with changes in the atmospheric circulation features in the lower and upper troposphere, a sustained increase in the rainfall at the observatory stations of Kerala and the island stations over the south-east Arabian sea is an essential feature of the monsoon onset. It is difficult to quantify these precisely and so the experience of the forecaster plays a key role in declaring the date of monsoon onset in individual years."
\end{abstract}

The IMD forecaster, while declaring the date of the MOK, has been taking into consideration subjectively the following features (Rao 1976): 1) the rainfall should be widespread over Kerala and adjacent areas, with large rainfall amounts at individual stations; 2) this rainfall persists over several days; 3) the lower-tropospheric westerlies in and around Kerala should be strong and deep; and 4) the air should be rich in moisture (high relative humidity) up to at least $500 \mathrm{hPa}$. However, there is no widely accepted objective definition of the MOK.

There also have been attempts to derive objective methods for the MOK. During the monsoon onset over
India dramatic changes are known to occur, including a rapid increase in the daily precipitation rate, an increase in the vertically integrated moisture, and an increase in kinetic energy, especially of the low-level flows (Krishnamurti 1985). Using daily rainfall data from a dense network of rain gauges in Kerala, Ananthakrishnan and Soman (1988) derived dates of MOK for south and north Kerala separately for the period from 1901 to 1980. They took the date of MOK as the first day of the transition from the light to heavy rainfall category with the provision that the average daily rainfall during the first 5 days after the transition should not be less than $10 \mathrm{~mm}$. Ananthakrishnan and Soman (1988) and Soman and Krishna Kumar (1993) have derived dates of the MOK using this method for the periods 1870-1980 and 1981-90, respectively. Fasullo and Webster (2003, hereafter FW03) have given another objective method of defining monsoon onset over India (but not over Kerala) using vertically integrated moisture transport instead of rainfall. Li and Yanai (1996) suggested that the reversal of land-sea thermal contrast associated with large temperature increase over the Tibetan Plateau in May-June acts as a climate driver of the ISM onset. Following this line of thinking, Goswami et al. (2006) proposed an ISM onset index based on reversal of the large-scale meridional temperature gradient in the upper troposphere south of the Tibetan Plateau. In recent studies, strengthening of low-level wind over the low-latitude Indian region has been noticed to be a good indicator of the ISM onset (Taniguchi and Koike 2006, hereafter TK06; Joseph et al. 2006). In particular, TK06 first emphasized the relationship between the Indian monsoon onset and abrupt strengthening of the low-level wind over the Arabian Sea $\left(7.5^{\circ}-20^{\circ} \mathrm{N}\right.$, $\left.62.5^{\circ}-75^{\circ} \mathrm{E}\right)$.

In summary, the subjective determination of the onset by IMD is not desirable as it is difficult to maintain its long-term consistency and sometimes causes substantial controversy (e.g., the onset in 2002). Use of Kerala rain gauge data is an objective method but the highly localized nature of the precipitation in this region with complex topography makes it extremely difficult to verify numerical model performance. Other objective methods using large-scale circulation features have an advantage for verification of numerical models, but existing indices do not have sufficiently high correlation with the IMD definition, thus these indices have not been recognized as a faithful representation of the ISM onset.

In the present study, we aim to derive an objective method for determining the date of the MOK by using characteristic changes in the large-scale atmospheric circulation with the hope that the resultant onset dates 


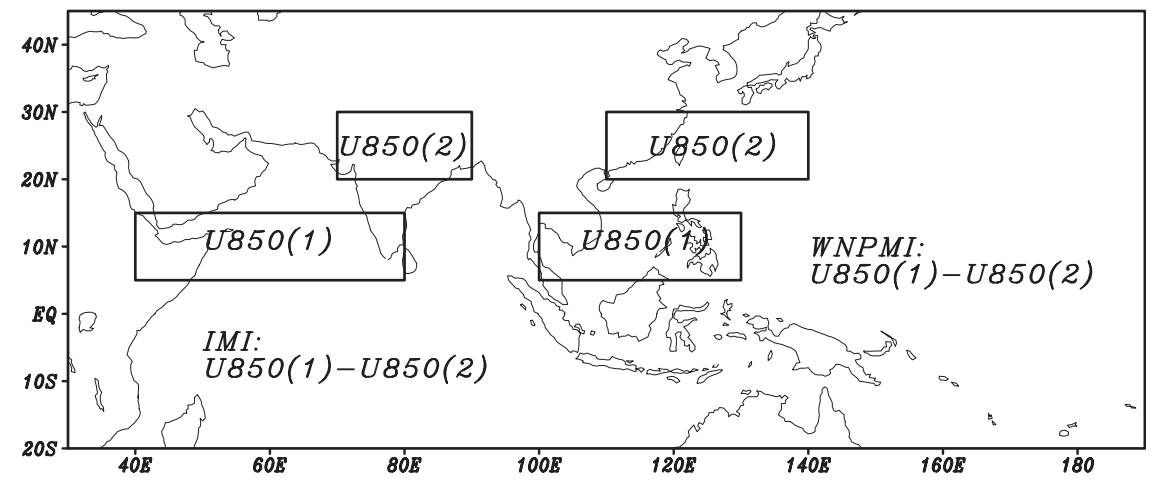

FIG. 1. Schematic diagram for the definition of the monsoon circulation indices: the Indian monsoon index (IMI) and the western North Pacific monsoon index (WNPMI). Solid boxes denote regions where the zonal winds are used to define the monsoon circulation indices (refer to the text for details). Adopted from Wang et al. (2001).

will faithfully represent both the historical IMD definition and the objective definition using local precipitation in the Kerala region. Such an index will combine the advantages of objectiveness and representativeness of both local precipitation changes and the large-scale circulation changes associated with the onset. Such an index will not only facilitate monitoring and adequate determination of the onset date in routine operations but also facilitate verification of numerical model performance and investigation of the climate factors that affect interannual and interdecadal variability of the ISM onset.

\section{Data}

The main dataset used in this work is the daily mean National Centers for Environmental PredictionNational Center for Atmospheric Research (NCEPNCAR) reanalysis data on a $2.5^{\circ} \times 2.5^{\circ}$ grid at the standard pressure levels for the 60 -yr period from 1948 to 2007. High-resolution ( $1^{\circ}$ latitude $\times 1^{\circ}$ longitude), gridded daily rainfall over India from IMD is also used to derive temporal variation of rainfall over Kerala from May to June. For this dataset, daily rainfall data for 1803 stations with a minimum $90 \%$ data availability during the analysis period (1951-2003) was used for interpolation so as to minimize the risk of generating temporal inhomogeneity in the dataset owing to varying station densities (Rajeevan et al. 2006). Daily averages of outgoing longwave radiation (OLR) data on a $2.5^{\circ}$ square grid, obtained using NOAA satellites, were used as a proxy for large-scale convective activity over the Indian subcontinent and the Indian Ocean. The daily OLR flux is available for the 29 -yr period from 1979 to 2007.

\section{Objective definition of the ISM onset using a large-scale westerly index}

It is not an easy task to objectively define monsoon onset and achieve the goals stated in the last paragraph of the introduction. In a previous study of the summer monsoon onset over the South China Sea (SCS) and East Asia, Wang et al. (2004) found that, while the climatological onset over the SCS is remarkably abrupt (simultaneous commencement across its large latitudinal range from $3^{\circ}$ to $22^{\circ} \mathrm{N}$ ), determination of the onset date for an individual year has been extremely controversial. Wang et al. (2004) have also shown that the summer monsoon onset over the SCS can be faithfully determined objectively by use of the $850-\mathrm{hPa}$ zonal winds averaged over the central SCS $\left(5^{\circ}-15^{\circ} \mathrm{N}, 110^{\circ}\right.$ $\left.120^{\circ} \mathrm{E}\right)$. In this section we explore the possibility for defining the ISM onset by using a similar approach as in Wang et al. (2004). The key issue is to determine the representative region of the southwest monsoon.

Wang and Fan (1999) found that "the enhanced convection over the Bay of Bengal and Indian subcontinents is coupled with reinforced monsoon circulation west of $80^{\circ} \mathrm{E}$ over India, the western Indian Ocean, and the tropical northern Africa." Based on this finding, Wang et al. (2001, hereafter WWL) defined a circulation index using the meridional shear of the $850-\mathrm{hPa}$ westerly, that is, the $850-\mathrm{hPa}$ zonal winds averaged over the southern region $\left(5^{\circ}-15^{\circ} \mathrm{N}, 40^{\circ}-80^{\circ} \mathrm{E}\right)$ minus that averaged over the northern region $\left(20^{\circ}-30^{\circ} \mathrm{N}, 70^{\circ}-90^{\circ} \mathrm{E}\right)$ (Fig. 1). This ISM circulation index, hereafter the WWL index, describes the variability of the low-level shear vorticity over the Indian monsoon trough, thus realistically reflecting the large-scale rainfall variability of the ISM. This is true for a broad range of time scales ranging from daily to seasonal. For instance, the 
(a)Corr. of daily OLR with $850 \mathrm{hPa}$ zonal wind
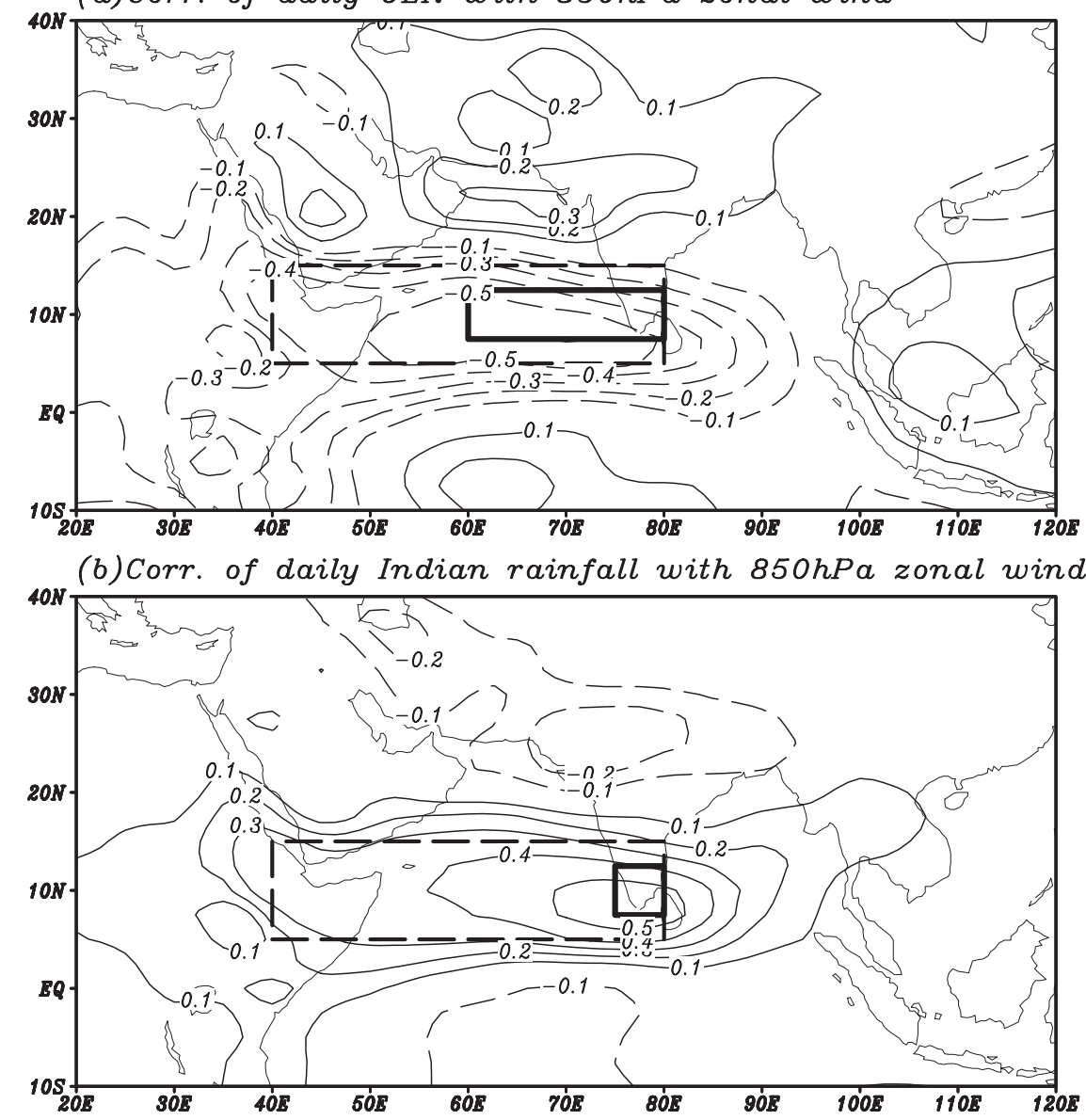

FIG. 2. (a) Correlation maps of daily 850 -hPa zonal wind with reference to the daily OLR averaged over $7.5^{\circ}-12.5^{\circ} \mathrm{N}, 60^{\circ}-80^{\circ} \mathrm{E}$ for the 29 -yr period from 1979 to 2007 . (b) Correlation maps of daily 850 -hPa zonal wind with reference to the daily rainfall averaged over the southern tip of India for the 53-yr period from 1951 to 2003. Daily correlation is calculated using daily data from 10 May to 20 June of each year. The solid line box indicates the region where the OLR and rainfall are averaged for correlation calculation. Also shown are the locations of the dashed line box for OCI definition.

June-September mean WWL index has a very high correlation coefficient (0.74) with the all Indian rainfall index (Parthasarathy et al. 1994) for the period 19482006. On the seasonal march, Syroka and Toumi (2004) have used the daily means of the WWL index to determine the withdrawal date of the ISM. Is the WWL index adequate for determination of the monsoon onset date?

The onset of the ISM is a large-scale phenomenon. Any onset index must reflect changes in both rainfall and large-scale circulation characteristics at the onset stage. How is the large-scale convection in southern India and adjacent ocean related to the low-level circulation in May and June? We take the OLR averaged over a large area from $7.5^{\circ}$ to $12.5^{\circ} \mathrm{N}, 60^{\circ}$ to $80^{\circ} \mathrm{E}$ as a measure of the intensity of deep convection near the southern tip of India (including Kerala) and the southeast Arabian Sea.
Figure 2 shows the correlation map of the daily $850-\mathrm{hPa}$ zonal wind with reference to the OLR $\left(7.5^{\circ}-12.5^{\circ} \mathrm{N}\right.$, $60^{\circ}-80^{\circ} \mathrm{E}$ ) for the period between 10 May and 20 June, from 1979 to 2007. The large negative correlation area extends from Somalia to Sri Lanka. This area covers roughly the rectangular region $5^{\circ}-15^{\circ} \mathrm{N}, 40^{\circ}-80^{\circ} \mathrm{E}$; for convenience, this region will be referred to as the southern Arabian Sea (SAS) region. The negative correlation implies that the enhanced $850-\mathrm{hPa}$ zonal wind in this SAS region is an essential feature that characterizes the large-scale deep-convection development over Kerala and the adjacent southeast Arabian Sea. To confirm the robustness of this rainfall-circulation relationship, we take the area-averaged rainfall covering the southern tip of the Indian subcontinent south of $12.5^{\circ} \mathrm{N}$ (Fig. 2b) and recalculate its correlation with respect to 


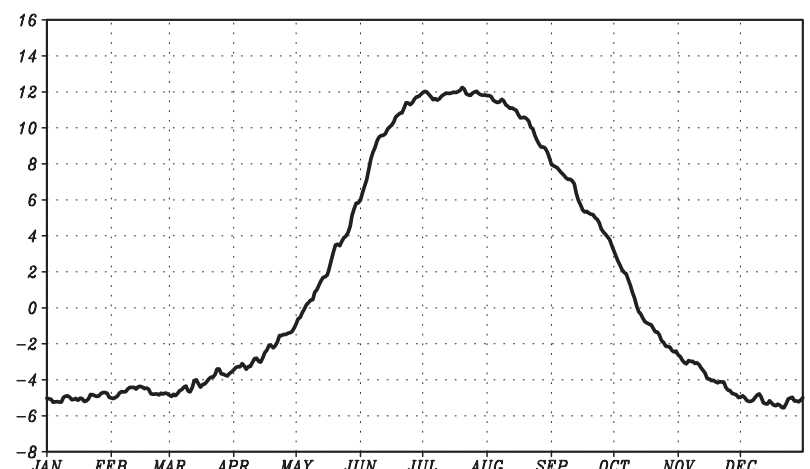

FIG. 3. Climatological seasonal cycle of the OCI over the interval calculated from daily NCEP-NCAR reanalysis between 1948 and 2007.

the $850-\mathrm{hPa}$ zonal wind for the period 10 May-20 June from 1951 to 2003. Significant correlation remains within the SAS region (Fig. 2b).

The SAS region is the southern region where the WWL index is defined. During the onset stage of the ISM, the variation of $850-\mathrm{hPa}$ zonal wind within the southern (SAS) region is more relevant to rainfall change in southern India than the zonal wind over the northern region. Here, we only use the $850-\mathrm{hPa}$ zonal wind averaged over the SAS $\left(5^{\circ}-15^{\circ} \mathrm{N}, 40^{\circ}-80^{\circ} \mathrm{E}\right)$ as an onset circulation index (OCI) of the ISM. In fact, we found that the onset date defined by the WWL index is well correlated with the IMD definition (correlation coefficient is 0.79 for the period from 1948 to 2007). The result obtained by using the WWL index is comparable to that obtained by using the OCI, which is 0.81 for the same period. The OCI used in the present study is the westerly index in the southern box $\left(5-15^{\circ} \mathrm{N}, 40-80^{\circ} \mathrm{E}\right)$ of the WWL index. We decided to use the southern box westerly wind speed as an OCI because it was simpler than the WWL index and has slightly better skill than that index.

The date of onset is defined as the first day when OCI exceeds $6.2 \mathrm{~m} \mathrm{~s}^{-1}$, with the provision that the OCI in the ensuing consecutive 6 days also exceeds $6.2 \mathrm{~m} \mathrm{~s}^{-1}$. The reason to take $6.2 \mathrm{~m} \mathrm{~s}^{-1}$ as a critical value is because the climatological mean onset date at Kerala is 1 June and, as shown in Fig. 3, the 850-hPa zonal wind averaged over the SAS exceeds $6.2 \mathrm{~m} \mathrm{~s}^{-1}$ on 1 June. The reason why we require the OCI greater than $6.2 \mathrm{~m} \mathrm{~s}^{-1}$ in the ensuing consecutive 6 days is to ensure that the strong westerly is not induced by a synoptic event; rather, it reflects a steady establishment of the strong southwest monsoon over the southern Arabian Sea. This definition of OCI meets the aforementioned three requirements: simple, objective, and representative of both the Kerala rainfall and large-scale circulation changes at the onset. Similar onset indices including other low-level zonal winds, are also tested, and no significant improvement is detected when other low-level wind information is incorporated into the OCI. Thus, we are confident that the information of the $850-\mathrm{hPa}$ zonal wind is adequate to monitor the MOK.

Figure 4 shows the time series of onset date defined by the OCI. For convenience of comparison, the onset date defined by IMD is also shown. It is seen that our objective OCI definition agrees very well with the subjective IMD definition. The linear correlation coefficient is 0.81 for the 60 -yr period $1948-2007$. The difference between the two onsets dates exceeding one standard deviation ( 7.3 days) occurs only in six years: 1950 (10 days), 1965 (10 days), 1977 (8 days), 1989 (13 days), 2000 (17 days), and 2007 (14 days). The most prominent discrepancy (greater than 10 days and a

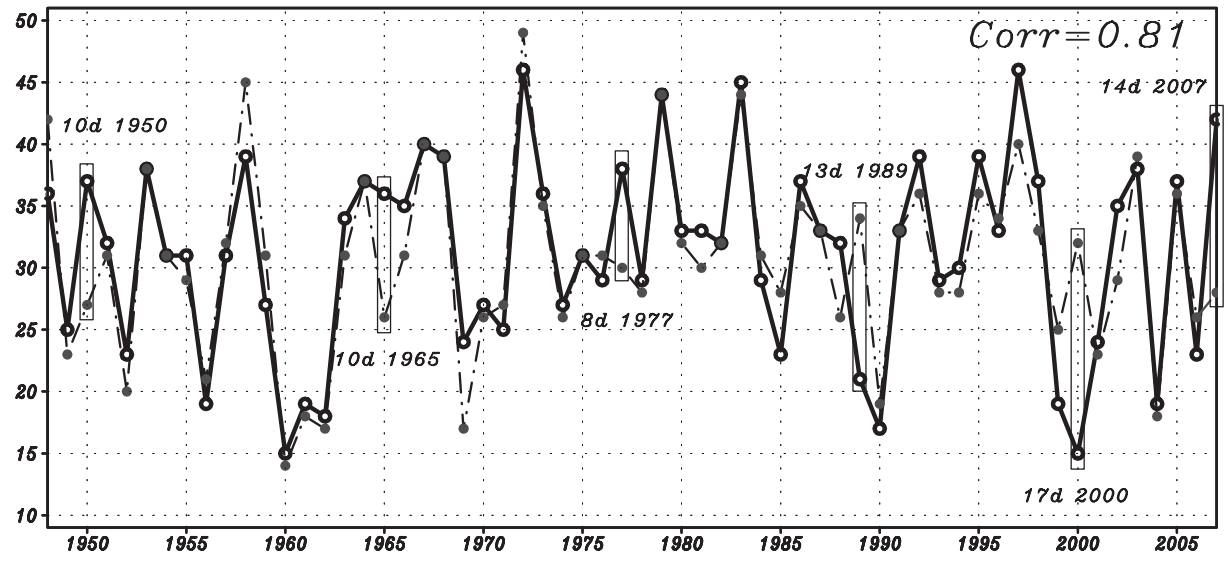

FIG. 4. Time series of onset dates defined by IMD (solid dots) and OCI (open circles) for the 60-yr period from 1948 to 2007. The six years with large discrepancies are each enclosed by a thin vertical box. Onset dates are counted from 1 May $(1$ May $=01, \ldots, 1$ June $=32, \ldots)$. 
TABLE 1. Correlation coefficients between the IMD onset and five different objective onset definitions for the available time periods.

\begin{tabular}{cccccc}
\hline \hline & SK (1948-90) & FW03 (1948-2000) & TK06 (1948-2007) & Goswami et al. (2006) (1950-2002) & OCI (1948-2007) \\
\hline IMD & 0.85 & 0.59 & 0.49 & 0.67 & 0.81 \\
\hline
\end{tabular}

tendencys to have an opposite signed anomaly) occurs only in three years (5\% of the total record). Why there is a large discrepancy in these three years will be analyzed in section 5. It will be seen that in these years, the discrepancy does not mean that the OCI definition is worse than the IMD definition. If these three extremely uncertain years is omitted, then the correlation coefficient between the IMD and OCI onset dates is 0.9.

Table 1 shows the correlation coefficients between the IMD onset and five different objective onset definitions: (i) south Kerala rainfall (SK) (Ananthakrishnan and Soman (1988), (ii) FW03 (Fasullo and Webster 2003), (iii) TK06 (Taniguchi and Koike 2006), (iv) Goswami et al. (2006), and (v) OCI. The IMD and SK have high correlation (0.85) for the available 43-yr period (1948-90). This is not surprising because the IMD definition includes Kerala rainfall. Note that for the same 43-yr period (1948-90), the correlation coefficient between the OCI and IMD is 0.86 , which is higher than the correlation between the SK and IMD. Compared to other circulation indices, the OCI has significantly better correlation with the IMD dates (Table 1).

\section{Evolution of the large-scale circulation associated with the ISM onset}

Composite evolution with respect to the onset date in each individual year may reveal the abruptness of the onset process. The rainfall evolutions over the southern tip of India for 53 years (1951-2003) are composited in terms of the IMD and OCI onset dates to show the rainfall evolution over Kerala from 40 days before to 30 days after onset (Fig. 5). It is clearly seen that both indices well signify an abrupt jump of rainfall over Kerala from preonset rainfall of $2-4 \mathrm{~mm} \mathrm{day}^{-1}$ to postonset rainfall of $8-10 \mathrm{~mm}$ day $^{-1}$.

To examine the two-dimensional evolution of onset progress, Fig. 6 shows the composite sequence of daily OLR and 850 -hPa zonal wind from 15 days prior to the onset ( -15 days) through onset day ( 0 days) that is defined by OCI. In Fig. 6, it can be seen that the first burst of summer monsoon rains initially occurs over the equatorial eastern Indian Ocean, Myanmar (formerlyBurma), Thailand, and the Andaman Sea about 15 days prior to the ISM onset. Strong low-level westerly winds driven by this strong convection prevail over the region to the south of the Indian subcontinent. Early convection band southwest of India and its accompa- nying westerly winds subsequently extend westward to $50^{\circ}-60^{\circ} \mathrm{E}$ along $10^{\circ} \mathrm{N}$, and their intensity further strengthens. Once the strong westerly wind and convection is well established over the region southwest of Kerala, the atmospheric condition is ready for commencement of the ISM season. A band of strong convection and westerly wind south of Kerala gradually advances northward to influence the Indian subcontinent afterward.

Within 2-3 days before monsoon onset over Kerala, the rainfall amount increases from 3 to $9 \mathrm{~mm} \mathrm{day}^{-1}$ (Fig. 5). Once the annual cycle is removed, the entire advancement of the monsoon over Kerala is dominated by a 40-50-day intraseasonal oscillation (ISO) signal showing a distinct dry episode and a subsequent wet episode immediately before and after the onset days, respectively.

To better understand intraseasonal processes related to the ISM onset and to obtain the intraseasonal precursor of the onset, it is helpful to examine the twodimensional evolution of convection and circulation features before, during, and after the onset on an intraseasonal time scale. For this purpose, a sequence of composite pentad means of OLR and $850-\mathrm{hPa}$ wind anomalies is plotted from the four pentads before to three pentads after the onset pentad (Fig. 7). The pentad means were obtained from the 29-yr OLR daily anomalies and the 60-yr 850-hPa-wind daily anomalies

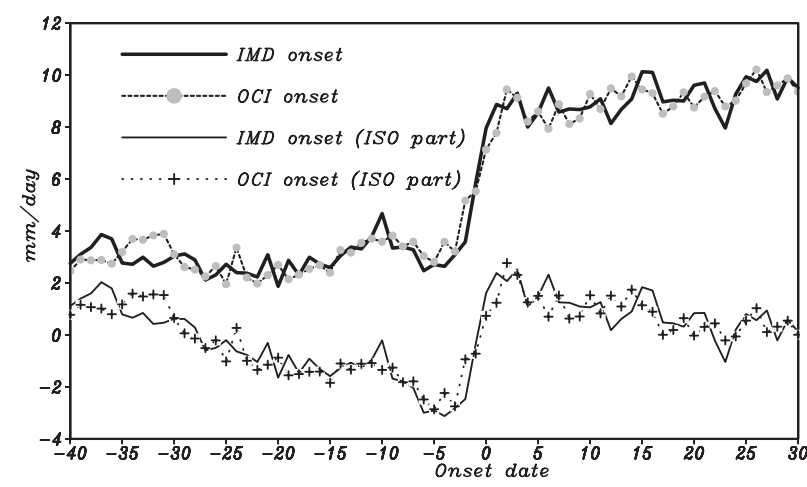

FIG. 5. Composite sequence of daily total rainfall (1951-2003) showing the antecedent and following evolution of ISM onset over the southern tip of India, including Kerala (region is shown as the box in Fig. 2b), from -40 to +30 days with respect to IMD onset and OCI onset. Dashed lines indicate the ISO signal with climatological annual cycle removed. Climatological annual cycle is defined as annual mean plus the first three harmonics with period 120,180 , and 360 days. Onset dates defined by IMD and OCI are denoted as zero day on the $x$ axis. 

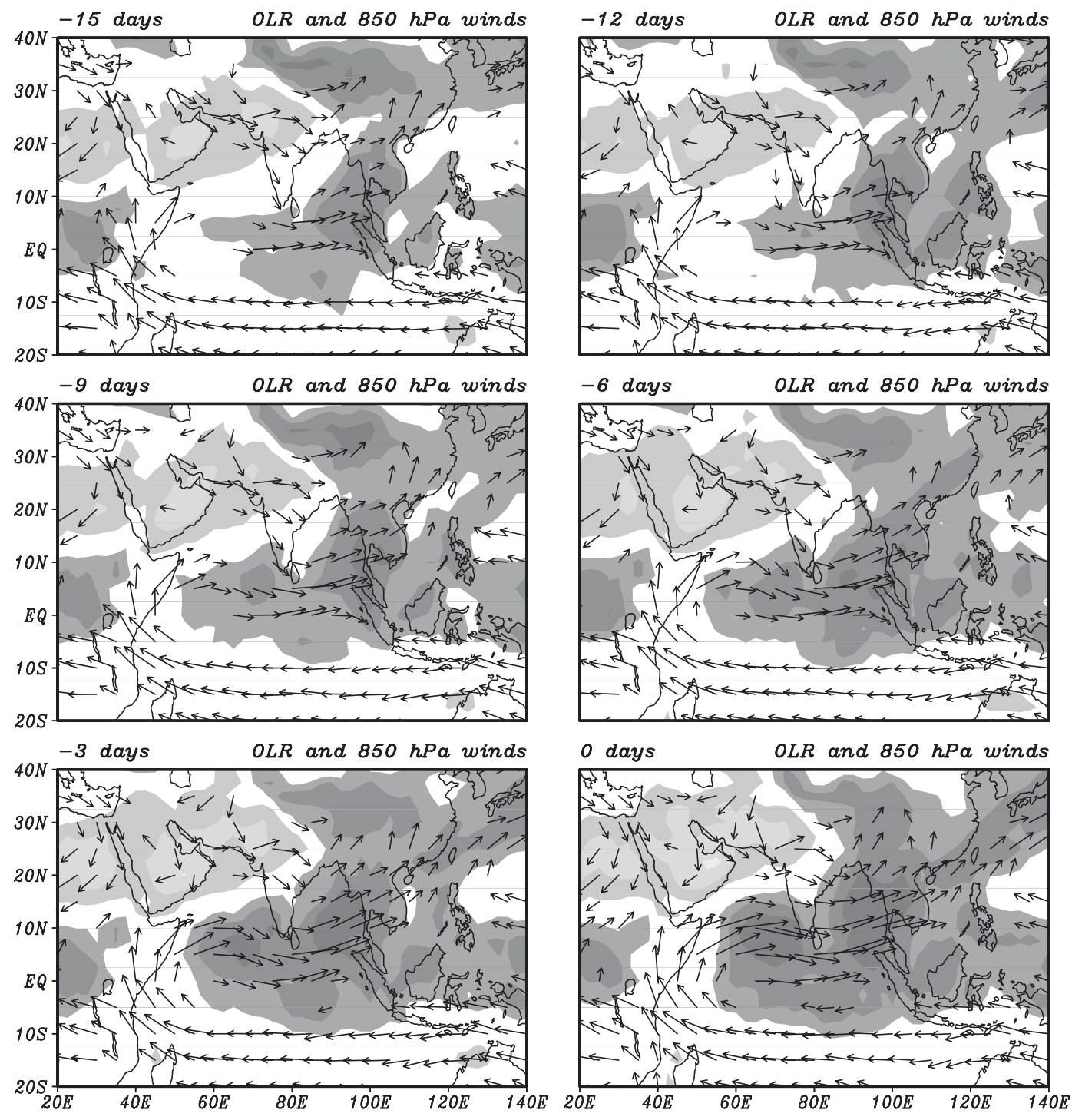

$15 \mathrm{~m} / \mathrm{s}$

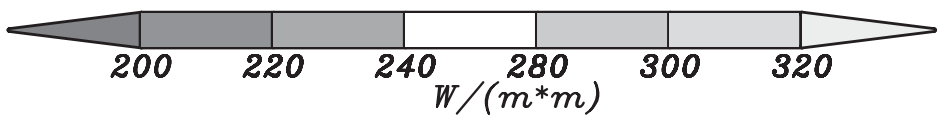

FIG. 6. Composite sequence of daily OLR and $850-\mathrm{hPa}$ winds (total fields) showing the antecedent evolution of ISM onset from day -15 to 0 in 3-day increments. For each time step, the composite of 850 -hPa winds and OLR (total fields) is constructed by averaging corresponding values from 29 years of OLR (1979-2007) and 60 years of 850-hPa winds (1948-2007). Winds with both zonal and meridional components less than $3 \mathrm{~m} \mathrm{~s}^{-1}$ are omitted.

by pentad averaging. The daily climatology was defined by the annual mean plus the first three harmonics with periods 120,180 , and 360 days.

About four pentads before onset, suppressed convection controls southern India and the southeast Arabian Sea, which in the subsequent two pentads continues to advance northeastward to cover most of the
Indian peninsula. This dry spell of ISO phase prior to the onset may cause serious heat waves over all of India. At pentad -2 , the easterly anomaly associated with the dry ISO spell over India generates cyclonic vorticity and convection anomalies over the equatorial western Indian Ocean. The new convective anomaly follows the pathway of the previous dry ISO to move 

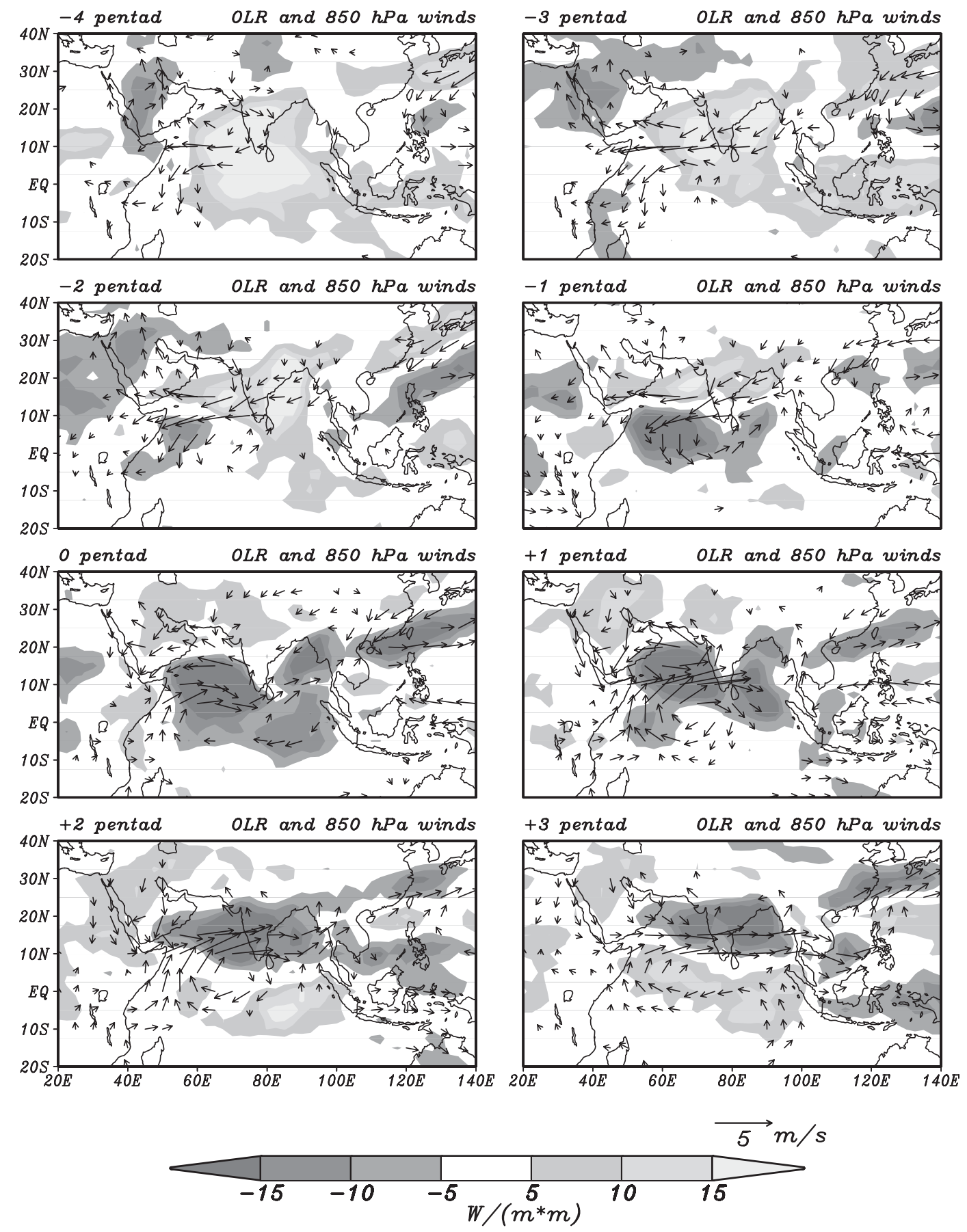

FIG. 7. As in Fig. 6 but using pentad-mean anomaly data (i.e., remove climatological annual cycle defined as annual mean plus first three harmonics with periods 120,180 , and 360 days). The timing runs from pentad -4 to +3 (the 0 pentad is the onset pentad). Shading represents OLR anomalies significant at the $95 \%$ confidence level based on a Student's $t$ test. Winds with both zonal and meridional components insignificant at the $95 \%$ confidence level are omitted.

northeastward. One pentad before the onset, an "onset vortex" appears southwest of Kerala. When the enhanced convection impinges on the southern tip of the peninsula, the ISM rainy season begins. After onset, the enhanced ISO convection continues to move northward and reaches $20^{\circ} \mathrm{N}$ at pentad +3 . Throughout the evolution, the $850-\mathrm{hPa}$ wind anomalies move in concert with the OLR anomalies and manifest themselves as a 

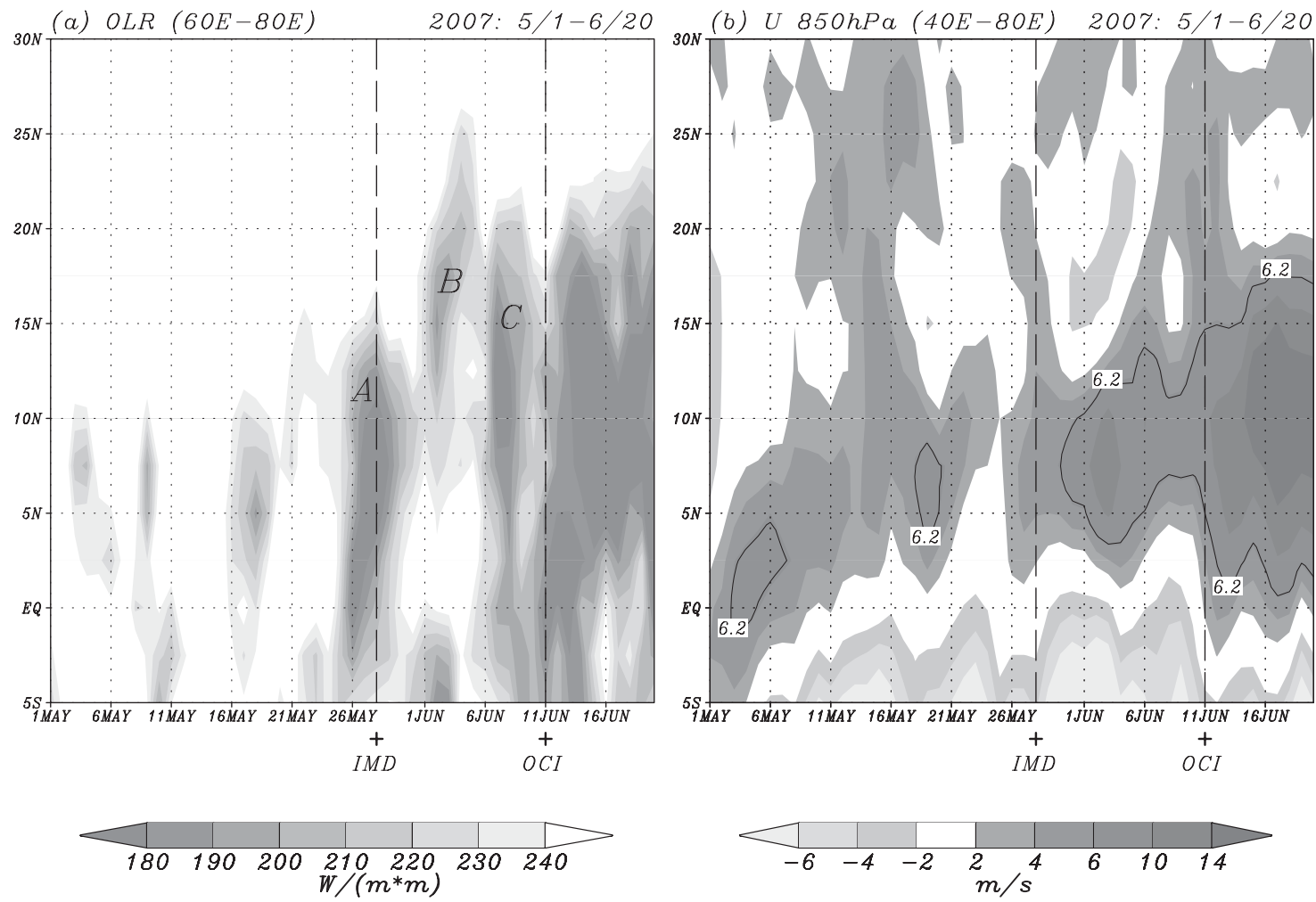

FIG. 8. Hovmöller diagram of (a) OLR field averaged between $60^{\circ}$ and $80^{\circ} \mathrm{E}$ and (b) the 850 -hPa zonal wind field averaged between $40^{\circ}$ and $80^{\circ} \mathrm{E}$ from 1 May to 20 June 2007. The IMD (left vertical dashed line) and OCI (right vertical dashed line) onset are marked. The three main convection centers occurring from late May to early June are marked A, B, and C.

Rossby wave response to the corresponding anomalous convective heating.

Over the Indian summer monsoon region, canonical northward-propagating 30-60-day ISO events have been observed and documented in detail (e.g., Yasunari 1979, 1980, 1981; Sikka and Gadgil 1980; Krishnamurti and Subrahmanyam 1982; Singh and Kripalani 1985, 1986; Wang and Rui 1990; Kemball-Cook and Wang 2001). The ISO characteristics, shown in Fig. 7, bear some resemblance but are not the same as the canonical event. A major difference is that the ISO convective anomaly associated with the MOK directly moves northeastward from the western north Indian Ocean without a clear equatorial eastward propagation.

This same sequence of convection over the north Indian Ocean and the associated $850-\mathrm{hPa}$ wind have been given in Joseph et al. $(1994,2006)$ for two composites of 10 and $9 \mathrm{yr}$, respectively. In the present paper, anomalies of convection are studied that reveal much more information. At pentads -5 to -2 , Joseph et al. (2006) found drying of the atmosphere over south India and the neighboring region (the inner box) in their Figs. $1 \mathrm{c}$ and $1 \mathrm{f}$, corresponding to the suppressed convection phase shown in this study.

\section{Discrepancy analysis}

Three cases $(1989,2000$, and 2007) are examined in detail here because these three cases have the largest differences and both OLR and wind data are available for these three years.

\section{a. The case of year 2007}

In 2007 the IMD onset is 28 May and the OCI date is 11 June. Hovmöller diagrams of the OLR field averaged between $60^{\circ}$ and $80^{\circ} \mathrm{E}$ and the 850 -hPa zonal wind field averaged between $40^{\circ}$ and $80^{\circ} \mathrm{E}$ are plotted in Fig. 8. In the OLR Hovmöller plot (Fig. 8a), there are three main convection centers occurring from late May to early June (marked as A, B, and C). Strong convection burst $\mathrm{B}$ is related to the formation of the super cyclonic storm Gonu over the east-central Arabian Sea (1-7 June), which crossed the Arabian Sea to the Oman coast. The IMD declared 28 May as the onset date when the first convection system A arrived at Kerala, and attributed the 8-9-day break between the two large-scale convection systems, A and C, to the disruption of supercyclone Gonu. The jet core of the $850-\mathrm{hPa}$ zonal wind gradually moved northward to $5^{\circ}-10^{\circ} \mathrm{N}$ after 5 May but with 

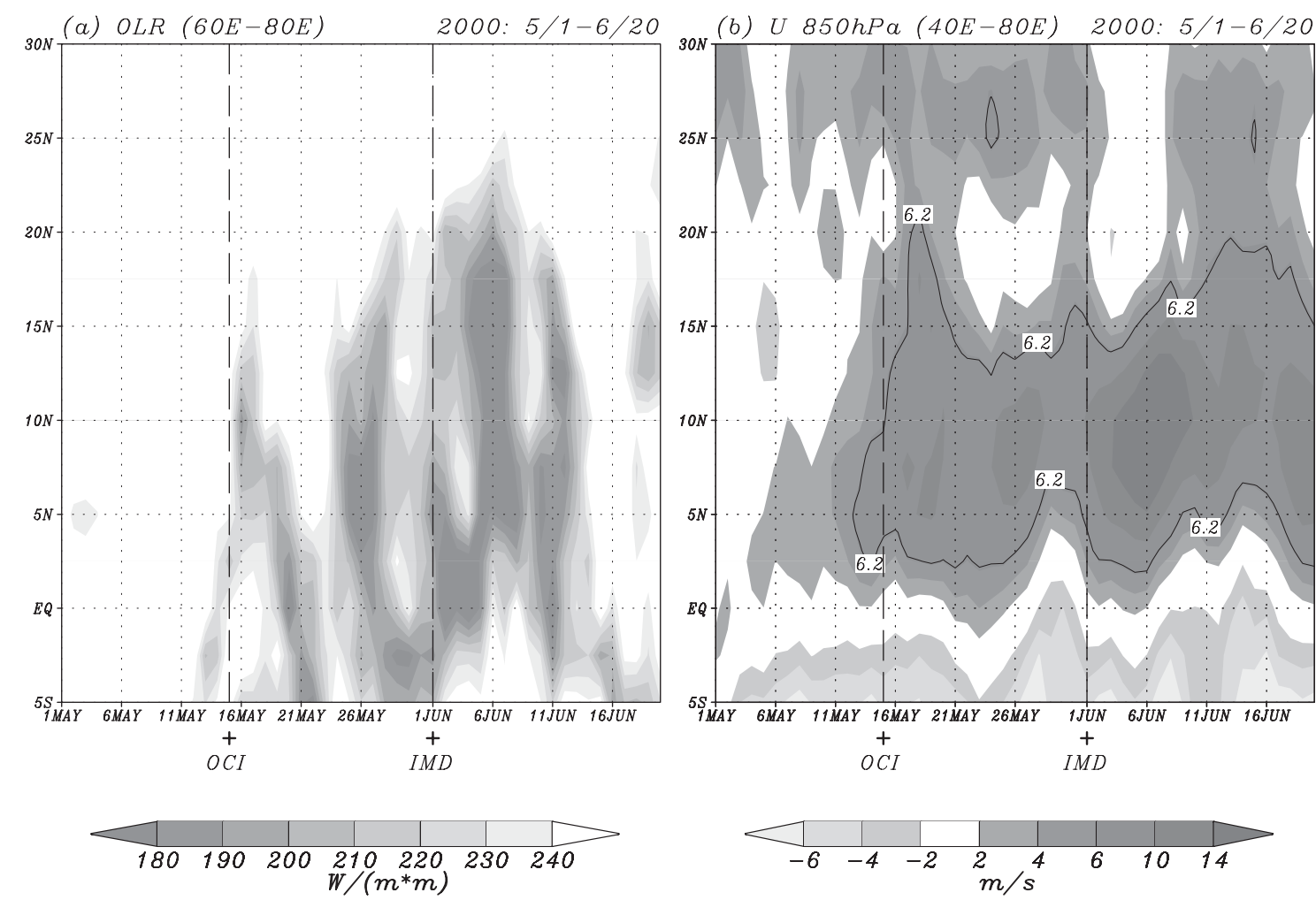

FIG. 9. As in Fig. 8 but for 2000.

relatively weak intensity (Fig. 8b). A second strengthening started on 1 June but only lasted for a few days. Because the OCI with magnitude larger than the critical value $\left(6.2 \mathrm{~m} \mathrm{~s}^{-1}\right)$ could not last more than 6 days, the second strengthening, started on 1 June, is not recognized by the OCI as the onset date. From 11 June, the $850-\mathrm{hPa}$ zonal wind was again reenergized so that the related large-scale convection system could bring widespread monsoon rainfall to India on 11 June. From the OLR plot, convection center $\mathrm{C}$ more likely indicates the commencement of the large-scale monsoon without a subsequent apparent break.

\section{b. The case of year 2000}

In 2000 the OCI onset date is 15 May, whereas the IMD onset date is 1 June; these two dates are marked in Fig. 9. On 15 May the OCI reached the critical value for monsoon onset (Fig. 9b), but there is very little rain in the longitude belt between $60^{\circ}$ and $80^{\circ} \mathrm{E}$ (Fig. 9a). The organized rain region began around the equator on 24 May and moved northward to Kerala latitudes by 26 May. This is probably the correct onset time in terms of rainfall. The OCI continued to increase from 26 May onward and the axis of strong winds began to move northward. The IMD declared monsoon onset on 1 June when the OCI reached a value of about $9 \mathrm{~m} \mathrm{~s}^{-1}$ and the axis of maximum zonal wind at $850 \mathrm{hPa}$ reached $\sim 10^{\circ} \mathrm{N}$.

We have examined the day-to-day variation of the 850-hPa wind and OLR over a large area around Kerala from several days before the OCI onset to several days after the IMD onset. On the day of OCI onset the southeast Arabian Sea had only a very small area with deep convection. The strong low-level wind established around 15 May to the southwest of Kerala is primarily driven by convection over the southeast Bay of Bengal (BOB) rather than by the convection over the southern tip of India (Fig. 10). But why the SAS westerly strongly responds to the $\mathrm{BOB}$ convection only in this year is not clear. The small area of convection in the southeast Arabian Sea grew in intensity and the corresponding area rapidly expanded after the OCI onset day and reached Kerala latitudes by 27 May (12 days after the OCI onset day). The widespread rains in Kerala after 1 June seem to be initiated from 27 May. The IMD could have declared monsoon onset on 27 May.

\section{c. The case of year 1989}

In 1989 the OCI designated the date of the MOK as 21 May, whereas the IMD declared the onset on 3 June. Hovmöller diagrams of OLR and the $850-\mathrm{hPa}$ zonal wind from 1 May to 20 June are presented in Fig. 11. 


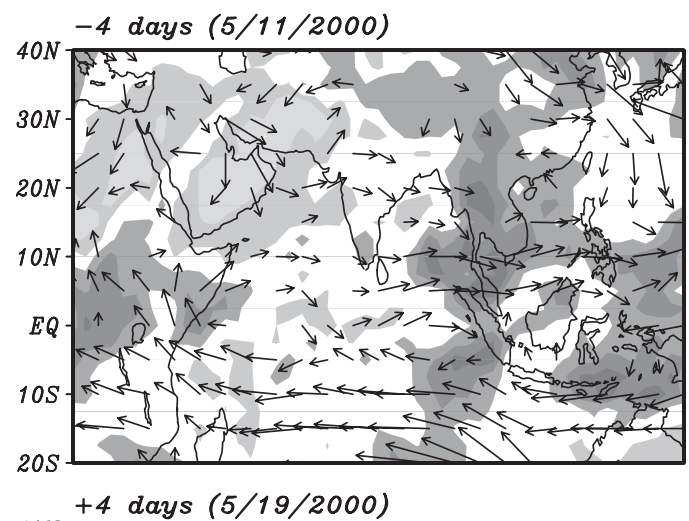

0 day (5/15/2000: OCI onset day)
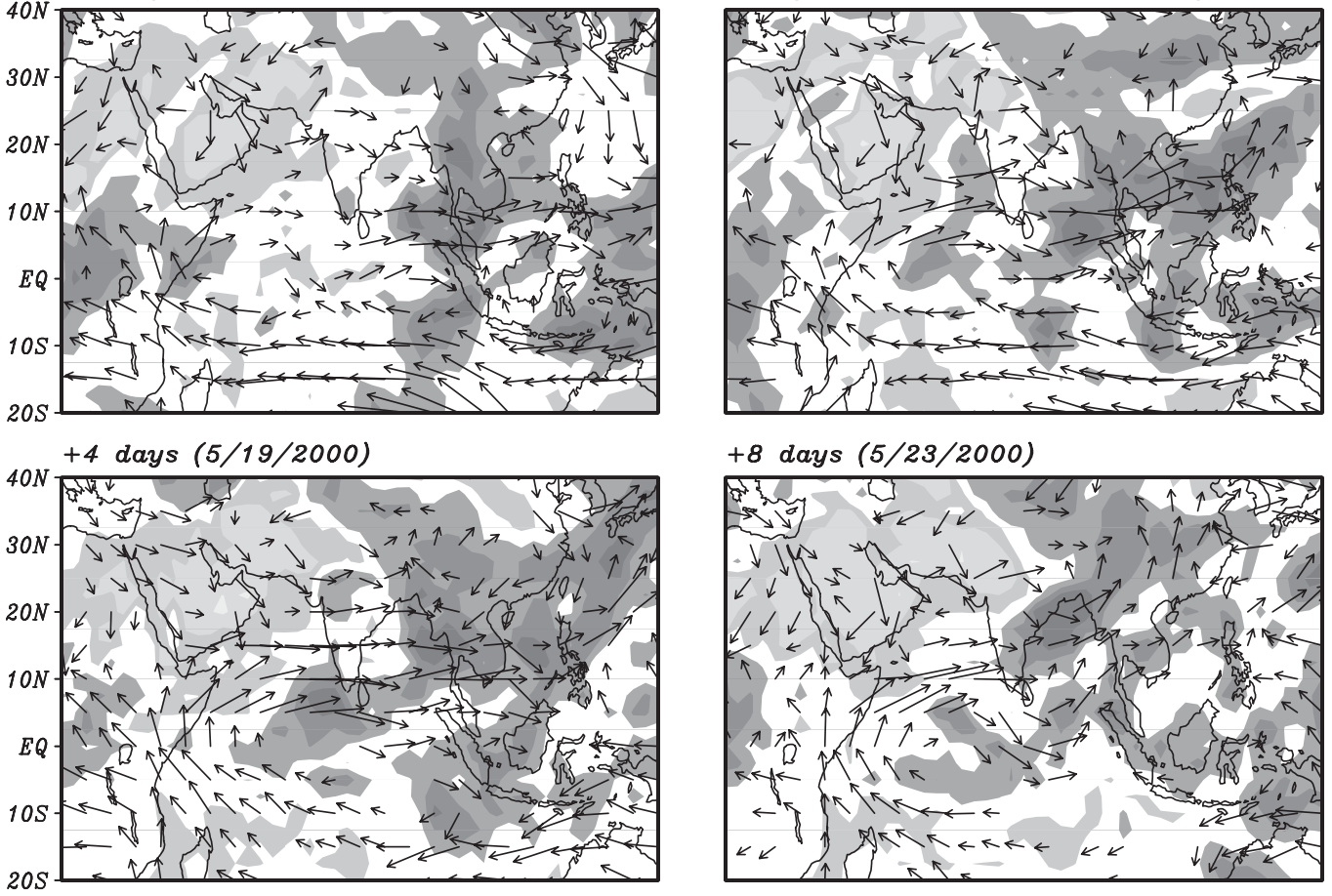

+8 days $(5 / 23 / 2000)$
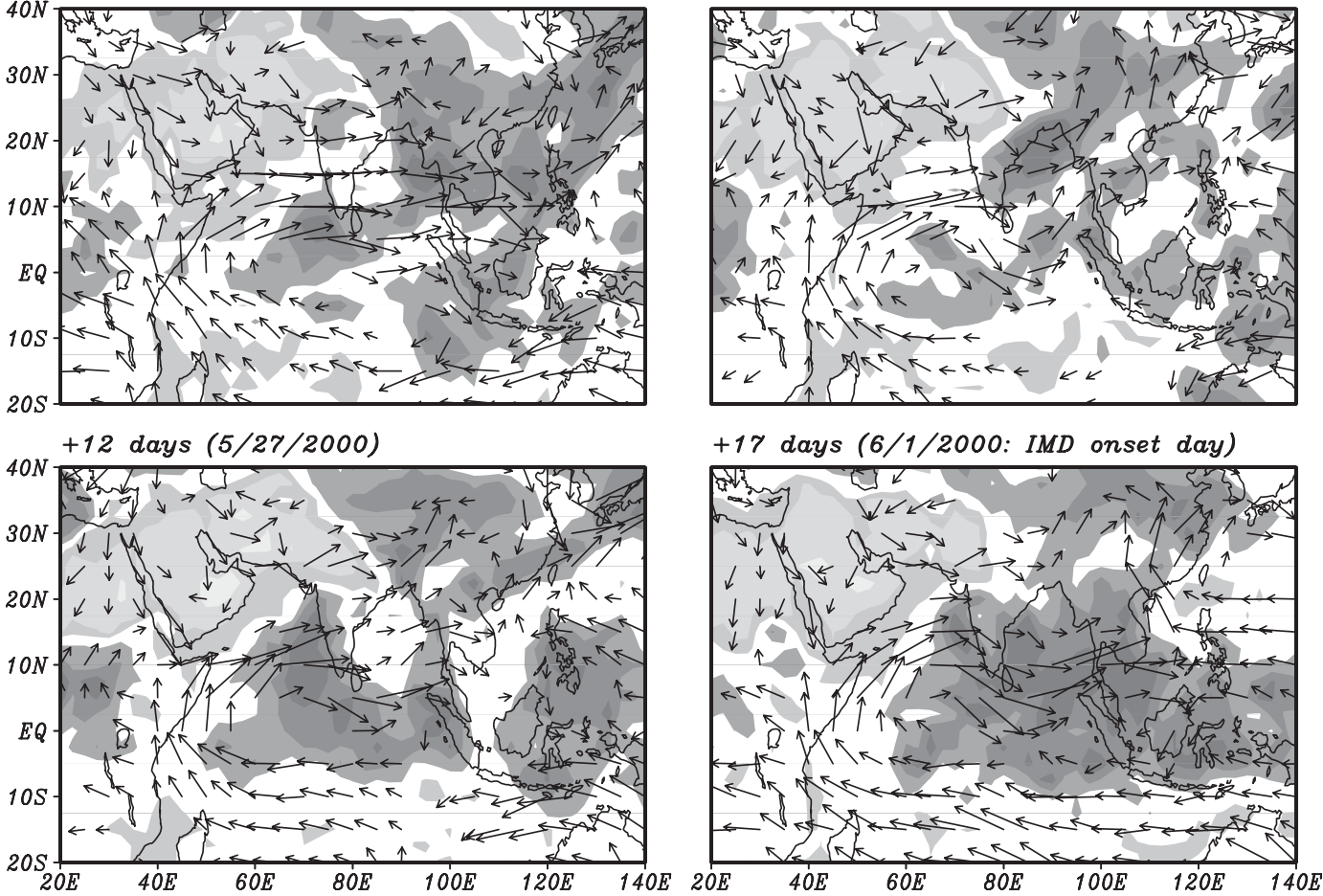

\section{$20 \mathrm{~m} / \mathrm{s}$}

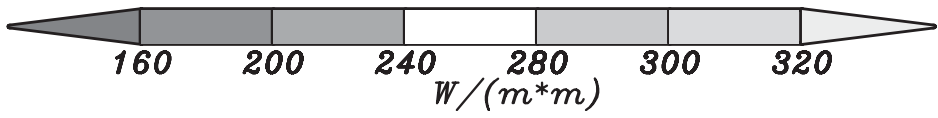

FIG. 10. Day-to-day variation of the $850-\mathrm{hPa}$ wind and OLR (total field) over a large area around Kerala, from 4 days before the OCI onset day to the IMD onset day in 2000 in 4-day increments. Shading shows OLR convection less than 240 and above $280 \mathrm{~W} \mathrm{~m}^{-2}$; vectors represent $850-\mathrm{hPa}$ winds. Winds with both zonal and meridional components less than $3 \mathrm{~m} \mathrm{~s}^{-1}$ are omitted.

The organized rain in the longitude belt $60^{\circ}-80^{\circ} \mathrm{E}$ originated near the equator on 10 May and slowly moved northward along with the maximum westerly axis. By 21 May the OCI reached the critical value for monsoon onset. The intense rainfall area, however, was still at latitudes south of Kerala. By 20 May south Kerala had heavy rains that lasted until 22 May, after which rain decreased at all latitudes. The IMD declared monsoon onset on 3 June when the next spell of heavy rains began simultaneously at latitudes $4^{\circ}-9^{\circ} \mathrm{N}$. As shown in Fig. 12, at the OCI onset date there is a large area of the southeast Arabian Sea covered by heavy rain but its northern limit just missed the Kerala latitude. From the OLR evolution, it is not unreasonable to 

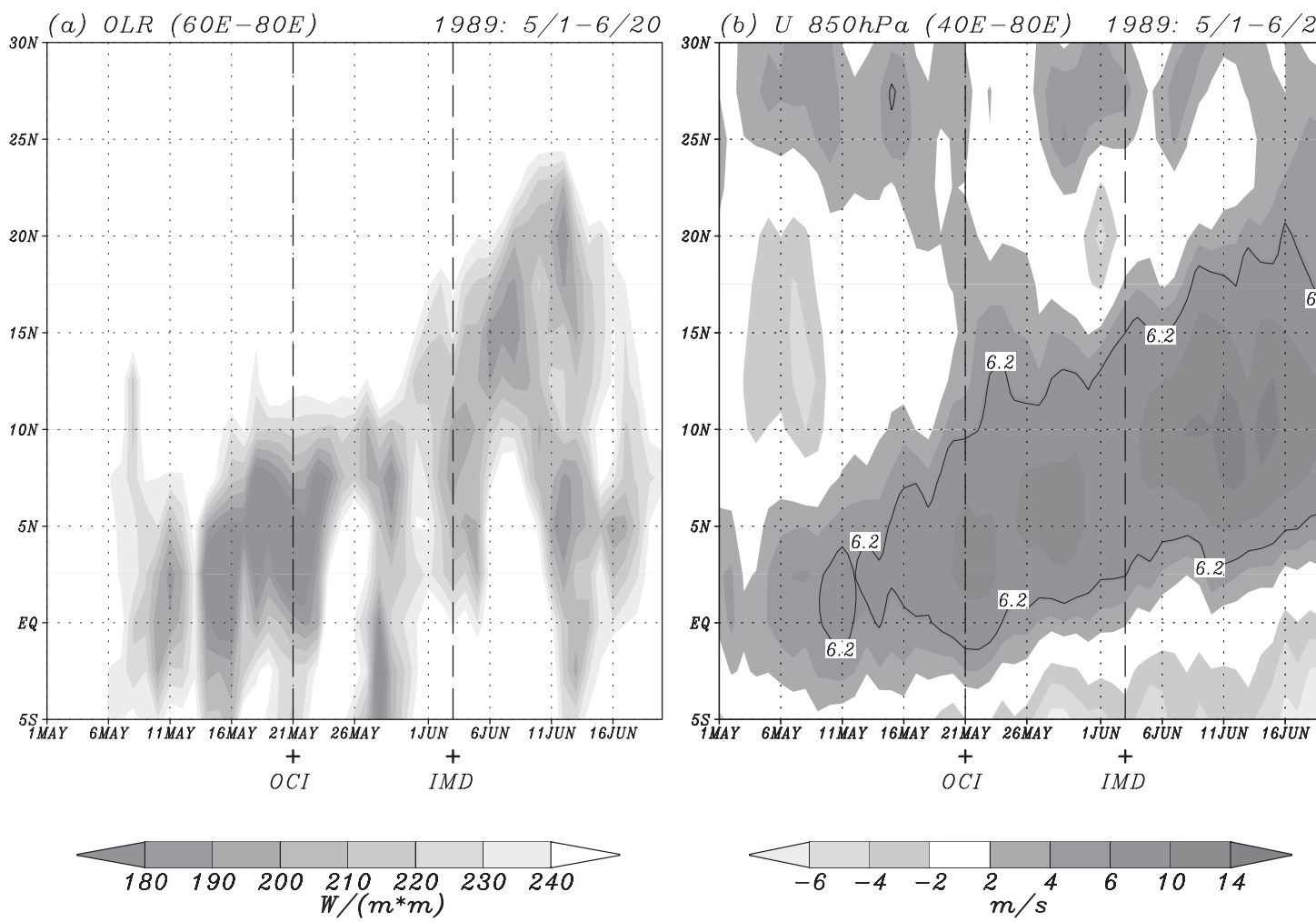

FIG. 11. As in Fig. 8 but for 1989.

consider onset on 21 May. The problem is that the westerly jet on 21 May is still to the south of $5^{\circ} \mathrm{N}$. Therefore, 25 May may be considered as the onset: both OLR and the westerly jet jumped to $6^{\circ} \mathrm{N}$ on 25 May.

\section{Conclusions}

An objective circulation index (OCI) for the ISM onset over Kerala is proposed based on analysis of the 60 years of the NCEP reanalysis data. The basic idea of OCI is that the burst of strong rainfall over Kerala from May to June is closely related to strengthening of the $850-\mathrm{hPa}$ zonal wind to the west of Kerala, extending from Somalia to Sri Lanka along $10^{\circ} \mathrm{N}$. The key region for monitoring the monsoon westerly is in the southern Arabian Sea $\left(5^{\circ}-15^{\circ} \mathrm{N}, 40^{\circ}-80^{\circ} \mathrm{E}\right)$. The quantity of $850-\mathrm{hPa}$ zonal wind averaged over the SAS $\left(5^{\circ}-15^{\circ} \mathrm{N}\right.$, $40^{\circ}-80^{\circ} \mathrm{E}$ ) is therefore adopted as an OCI to define the ISM onset: the first day of the period when the OCI continuously exceeds $6.2 \mathrm{~m} \mathrm{~s}^{-1}$ for more than seven days (including the onset day). The SAS covers a large region and thus the OCI is insensitive to synoptic variability; rather, it signifies the rapid change in large-scale circulation that occurs during the monsoon transitions.

This index also adds new insight into the seasonal transition of the Indian monsoon and its relationship with the intraseasonal variability of tropical convection. The composite of the total field of circulation and convection prior to objective onset dates shows a westward extension of the strong convection center and related $850-\mathrm{hPa}$ westerly wind from the equatorial eastern Indian Ocean to the southeast Arabian Sea. Once the strong convection and westerly wind is well established to the southwest of Kerala, a large-scale stagnating rainfall belt covering the entire equatorial Indian Ocean starts to progress northward across India and bring widespread rainfall over the western part of the country. The composite ISO map suggests a phase relationship between the northward propagating 30-60-day ISO and the timing of onset. From mid-May to mid-June, the large-scale atmospheric and land surface conditions are ready for the onset to start. Arrival of a wet phase of the ISO may help to trigger and accelerate the ISM onset over Kerala, whereas the dry phase may delay onset and induce a heat wave over India that preceds onset of the rainy season.

The 60-yr onset dates defined by the OCI are highly correlated with IMD onset dates, with the exception of only six years showing a large discrepancy. The analysis of three of these years $(1989,2000$, and 2007) suggests that our method has comparable ability as the IMD onset in reflecting large-scale climate transition during the onset processes for these three years. 

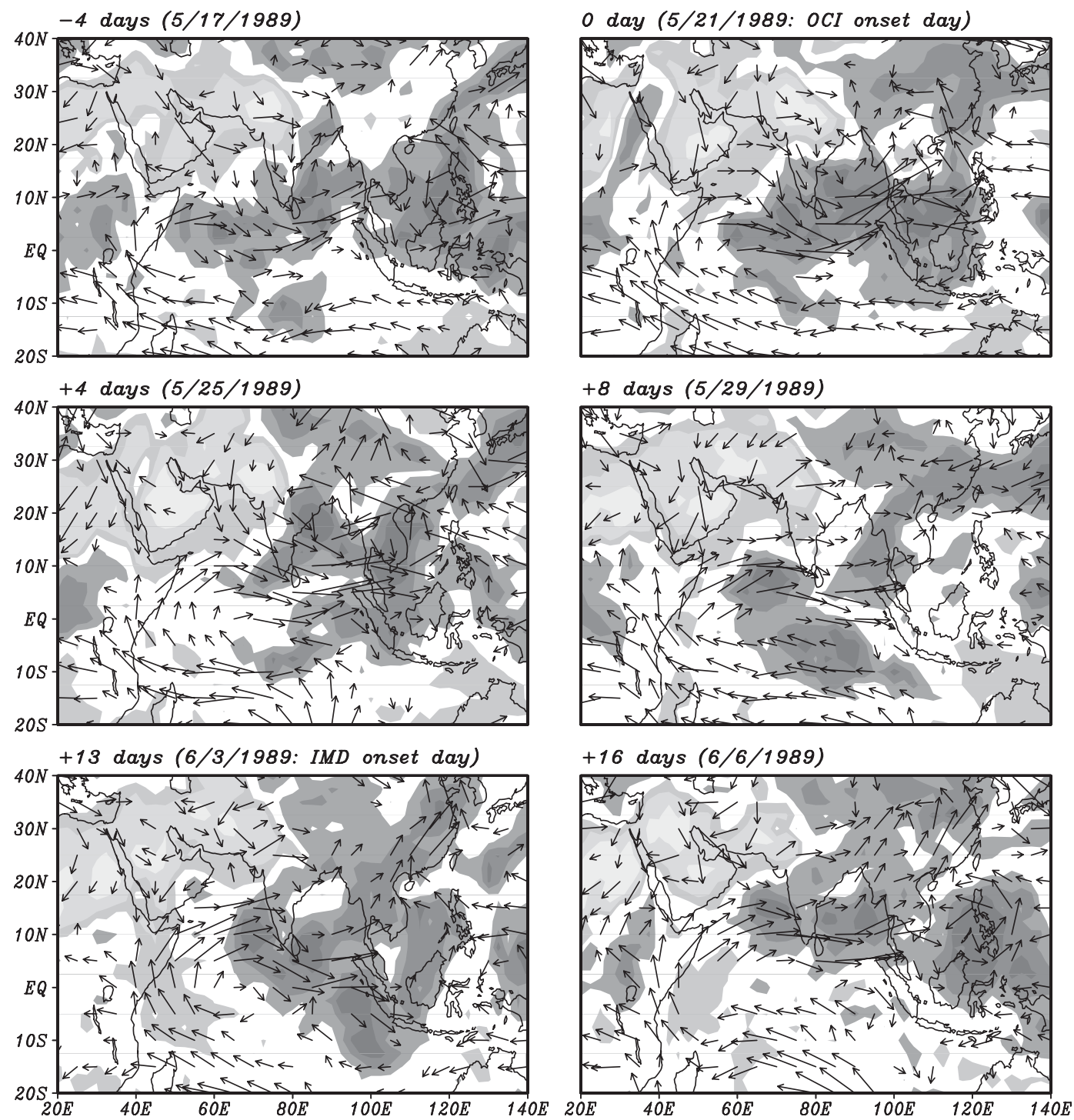

$20 \mathrm{~m} / \mathrm{s}$

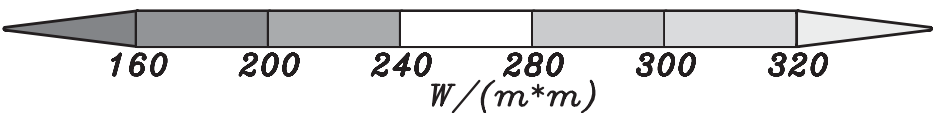

FIG. 12. As in Fig. 10 but for 1989.

Applying OLR and the low-level wind as a criterion to distinguish extraordinary early and late onset using the OCI, it is possible to search for significant climate precursors that may cause exceptional early or late ISM onset. In addition, OCI could be used as a valuable criterion for assessing a general circulation model's ability in simulating ISM processes. Indeed, ISM onset is a large-scale phenomenon and its transition should be reflected by some variable of the atmosphere. In this study, we point out that the 850 -hPa zonal wind over $5^{\circ}-15^{\circ} \mathrm{N}, 40^{\circ}-80^{\circ} \mathrm{E}$ is such a sensitive parameter to quantify the abrupt transition of large-scale atmospheric preconditions associated with the ISM onset.

Acknowledgments. This study has been supported by the National Science Foundation/Climate Dynamics Program Award ATM-0647995. The authors appreciate the anonymous reviewers' comments on an early version of the manuscript, which led to significant improvement. 


\section{REFERENCES}

Ananthakrishnan, R., and M. K. Soman, 1988: The onset of the southwest monsoon over Kerala: 1901-1980. J. Climatol., 8, 283-296.

— U. R. Acharya, and A. R. Ramakrishnan, 1967: On the criteria for declaring the onset of southwest monsoon over Kerala. India Meteorological Department Forecasting Manual IV 18.1, 1-52.

Deshpande, V. R., R. H. Kripalani, and D. K. Paul, 1986: Some facts about monsoon onset dates over Kerala and Bombay. Mausam, 37, 467-470.

Fasullo, J., and P. J. Webster, 2003: A hydrological definition of Indian monsoon onset and withdrawal. J. Climate, 16, 3200-3211.

Findlater, J., 1969: A major low level air current near the Indian Ocean during the northern summer. Quart. J. Roy. Meteor. Soc., 95, 362-380.

Ghanekar, S. P., P. V. Puranik, and U. V. Bhide, 2003: Forecasting the onset of monsoon over Kerala using the peak in premonsoon convective activity over south peninsular India. Mausam, 54, 645-652.

Goswami, B. N., G. Wu, and T. Yasunari, 2006: The annual cycle, intraseasonal oscillations, and roadblock to seasonal predictability of the Asian summer monsoon. J. Climate, 19, 5078-5099.

IMD, 1943: Climatological Atlas for Airman. India Meteorological Department, $100 \mathrm{pp}$.

Joseph, P. V., and P. V. Pillai, 1988: 40-day mode of equatorial trough for long range forecasting of Indian summer monsoon onset. Curr. Sci., 57, 951-954.

_- and S. Sijikumar, 2004: Intraseasonal variability of the lowlevel jet stream of the Asian summer monsoon. J. Climate, 17, 1449-1458.

_, J. K. Eishcheid, and R. J. Pyle, 1994: Interannual variability of the onset of the Indian summer monsoon and its association with atmospheric features, El Niño, and sea surface temperature anomalies. J. Climate, 7, 81-105.

$\longrightarrow$, K. P. Sooraj, and C. K. Rajan, 2006: The summer monsoon onset process over South Asia and an objective method for the date of monsoon onset over Kerala. Int. J. Climatol., 26, 1871-1893.

Kemball-Cook, S., and B. Wang, 2001: Equatorial waves and airsea interaction in the boreal summer intraseasonal oscillation. J. Climate, 14, 2923-2942.

Krishnamurti, T. N., 1985: Summer Monsoon Experiment-A review. Mon. Wea. Rev., 113, 1590-1626.

— , and D. Subrahmanyam, 1982: The 30-50 day mode at $850 \mathrm{mb}$ during MONEX. J. Atmos. Sci., 39, 2088-2095.

Kung, E. C., and T. A. Shariff, 1982: Long-range forecasting of the Indian summer monsoon onset and rainfall with upper air parameters and sea surface temperature. J. Meteor. Soc. India, 60, 672-681.

Li, C., and M. Yanai, 1996: The onset and interannual variability of the Asian summer monsoon in relation to land-sea thermal contrast. J. Climate, 9, 358-375.

Parthasarathy, B., A. A. Munot, and D. R. Kothawale, 1994: All India monthly and seasonal rainfall series: 1871-1993. Theor. Appl. Climatol., 49, 217-224.
Rajeevan, M., and D. P. Dube, 1995: Long range prediction of monsoon onset over Kerala. Mausam, 46, 287-290.

_ J. Bhate, J. D. Kale, and B. Lal, 2006: High resolution daily gridded rainfall data for the Indian region: Analysis of break and active monsoon spells. Curr. Sci., 91, 296-306.

Ramdas, L. A., P. Jagannathan, and S. Gopala Rao, 1954: Prediction of date of establishment of southwest monsoon along west coast of India. Indian J. Meteor. Geophys., 5, 305-314.

Rao, Y. P., 1976: South West Monsoon. India Meteorological Department, 376 pp.

Reddy, S. J., 1977: Forecasting the onset of southwest monsoon over Kerala. Indian J. Meteor. Geophys., 28, 113-114.

Saha, S., and K. R. Saha, 1980: A hypothesis on onset, advance and withdrawal of Indian summer monsoon. Pure Appl. Geophys., 118, 1066-1075.

Sikka, D. R., and S. Gadgil, 1980: On the maximum cloud zone and the ITCZ over Indian longitudes during the southwest monsoon. Mon. Wea. Rev., 108, 1840-1853.

Singh, S. V., and R. H. Kripalani, 1985: The south to north progressions of rainfall anomalies across India during the summer monsoon season. Pure Appl. Geophys., 123, 624-637.

— and - 1986: Application of extended empirical orthogonal function analysis to interrelationships and sequential evolution of monsoon fields. Mon. Wea. Rev., 114, 1603-1610.

Soman, M. K., and K. Krishna Kumar, 1993: Space-time evolution of meteorological features associated with the onset of Indian summer monsoon. Mon. Wea. Rev., 121, 1177-1194.

Subbaramayya, I., and O. S. R. U. Bhanukumar, 1978: The onset and northern limit of southwest monsoon. Meteor. Mag., 107, $37-47$.

Syroka, J., and R. Toumi, 2004: On the withdrawal of the Indian summer monsoon. Quart. J. Roy. Meteor. Soc., 130, 989-1008.

Taniguchi, K., and T. Koike, 2006: Comparison of definitions of Indian summer monsoon onset: Better representation of rapid transitions of atmospheric conditions. Geophys. Res. Lett., 33, L02709, doi:10.1029/2005GL024526.

Wang, B., and H. L. Rui, 1990: Synoptic climatology of transient tropical intraseasonal convection anomalies: 1975-1985. Meteor. Atmos. Phys., 44, 43-61.

_ , and Z. Fan, 1999: Choice of South Asian summer monsoon indices. Bull. Amer. Meteor. Soc., 80, 629-638.

_, R. Wu, and K.-M. Lau, 2001: Interannual variability of Asian summer monsoon: Contrasts between the Indian and western North Pacific-East Asian monsoons. J. Climate, 14, 4073-4090.

—, H. Lin, Y. Zhang, and M. M. Lu, 2004: Definition of South China Sea monsoon onset and commencement of the East Asia summer monsoon. J. Climate, 17, 699-710.

Yasunari, T., 1979: Cloudiness fluctuation associated with the Northern Hemisphere summer monsoon. J. Meteor. Soc. Japan, 57, 227-242.

, 1980: A quasi-stationary appearance of 30-40 day period in the cloudiness fluctuation during summer monsoon over India. J. Meteor. Soc. Japan, 58, 225-229.

_ 1981: Structure of an Indian summer monsoon system with around 40-day period. J. Meteor. Soc. Japan, 59, 336-354. 